\title{
Forest Loss Triggers in Cameroon: A Quantitative Assessment Using Multiple Linear Regression Approach
}

\author{
Epule Terence Epule (Corresponding author) \\ Institute of Environmental Sciences, University of Quebec at Montreal (UQAM) \\ Case postale 8888, succ Centre-Ville, Montréal (QC), H3C 3P8, Canada
}

Tel: 1-514-987-3000 ext 3041 E-mail: epule.terence_epule@courrier.uqam.ca

\begin{abstract}
Changhui Peng
Institute of Environmental Sciences, University of Quebec at Montreal (UQAM)

Case postale 8888, succ Centre-Ville, Montréal (QC), H3C 3P8, Canada
\end{abstract}

Tel: 1-514-987-3000 ext 1056 E-mail: peng.changhui@uqam.ca

Laurent Lepage

Institute of Environmental Sciences, University of Quebec at Montreal (UQAM)

Case postale 8888, succ Centre-Ville, Montréal (QC), H3C 3P8, Canada

Tel: 1-514-987-3000 ext $3509 \quad$ E-mail: lepage.laurent@uqam.ca

\author{
Zhi Chen \\ Department of Building, Civil and Environmental Engineering, Concordia University \\ 1515 St Catherine West, Montreal (QC), H3G 2W1, Canada \\ Tel: 1-514-848-2424 ext 8775 E-mail: zhichen@bcee.concordia.ca
}

Received: May 23, 2011 Accepted: June 23, 2011 doi:10.5539/jgg.v3n1p30

\begin{abstract}
The triggers of forest area loss in Cameroon have not been properly understood. The measures used to curb forest area loss have been simplistic, generalized with no clear cut knowledge of the specific role of different potential factors. This study aims at investigating the hypothesis that population growth is the main cause of loss in forest area. This study will be able to identify what factors are of more significance in the causal equation. The open $\mathrm{R}$ programming software has been used to produce multiple linear regression models. The correlation between the dependent variable and the independent variables was established by a correlation matrix and the strength of the models tested by power analysis. The results supports the hypothesis that population growth is the most dominant cause of deforestation in Cameroon while arable production and permanent crop land and arable production per capita index are second and third respectively.
\end{abstract}

Keywords: Forest loss, Population, Arable and permanent crop land, Arable production per capita index, multiple linear regressions

\section{Introduction}

Tropical forests are widely known as key terrestrial ecosystems for our life support system. They include not only environmental and economic factors but also socio-cultural components of human life (Arementeras et al., 2010). Most of the models of forest loss that have been developed in recent years include a combination of economic, demographic, institutional, climatic variables whose share strength in the net forest loss tends to vary spatially and temporally (Arementeras et al., 2010). To adequately understand the role of forest loss in the earth's future we need to not only measure when and where the changes have occurred but also have a good understanding of the causal factors that are specific to different countries ( Lambin \& Ehrlich, 1997). The 
development of empirical models of the forces responsible for deforestation in a given country is of importance because it enhances understanding of the specific situations in given countries and also makes policies towards mitigation more effective (Mertens \& Lambin, 1997).

The causes of deforestation in sub-Saharan Africa inter alia include population growth, slash and burn fires, fuel wood usage, agricultural expansion, cattle rearing and the economic logging factor inter alia (Mertens \& Lambin, 1997; Agvei, 1997). In spite of this wealth of knowledge on the causes of forest area change in Sub-Saharan Africa, the spatio-temporal variations inherent in different countries make it difficult to reliably assert which factors are dominant in the different countries. The repercussions are that policy and interventions to curb deforestation remains a daunting task since measures to curb land cover change are highly simplistic and generalized without emphasis on the specifics of different countries (Clement \& Amezaga, 2008; Armenteras et al., 2010).

As such, conventional analysis of the causes of forest loss in Sub-Saharan Africa have been described as either too simplistic, generalized or out of course (Agarwal et al., 2005). The question, why are the observed factors the drivers of deforestation and reforestation in one situation and not the other? has not been clearly answered (Clement \&Amezaga, 2008).

Cameroon has a total area of $465400 \mathrm{~km}^{2}$, about $60 \%$ of this is covered by forest which is equivalent to about 28 million hectares in area. From the 28 million hectares, about 12 million hectares are covered by tropical rainforest, an equivalent of $42 \%$ of the total forest area (FAOSTAT, 2010). Currently, about 220000 hectares of forests are lost each year in Cameroon; this gives rates of between 0.6-1.0 \% of annual loss of forest in Cameroon (Forest Resource Assessment report, the Food and Agricultural Organization (FAO), 1990; FAO, 2010).

Many articles have discussed deforestation in Africa (Arementeras et al., 2010; Lambin \& Ehrlich, 1997; Mertens \& Lambin, 1997; Agvei, 1997; Agarwal et al., 2005 \& Oyono, 2005). However, a lot of gaps in research still exist in many countries in general and Cameroon in particular. This is because there has been a remarkable absence of a systematic and adequate analysis of the major factors that cause deforestation (Salam \& Noguchi, 1998). Most of the papers written on the subject on Africa, Asia and Latin America have simply attributed the loss of forest to population growth, shifting cultivation, economic development, misplaced and poorly guided government policies, conversion of forest land to agricultural land, commercial logging and fuel wood fetching among others without any tests of hypotheses. As such, these studies lack a lot of empirical support to validate the stated hypothesis and have not been able to classify the causes to come out with a rank of causal factors. The lack of empirical support is evident as most of the past studies have been mainly descriptive with generalizations of the causes of deforestation (Salam \& Noguchi, 1998; Allan \& Barnes, 1985; Fischer \& Vasseur, 2000; Carr et al., 2005).

The objectives of this study are to examine the causes of deforestation in Cameroon through statistical models determined by a multiple linear regression approach which will enable a classification of the most important causal factors in the Cameroonian forest loss model. The key variables that will be analyzed in the linear regression equation will be: forest area and cattle stock, arable output per capita, arable and permanent crop land, rainfall, trade in forest products, populations and fuel wood. Therefore, to be able to control the ecological and social effects of deforestation and to enact adequate policies, it becomes important to have a close look at the causes on a broad national scale. To our knowledge, this is the first study that has applied this approach in looking at the causes of deforestation in Cameroon. The approach remains vital because if we plan to subvert food and water scarcity as is the case in Somalia and," If we hope to conserve forests, we must understand the reasons that people are destroying them" (Acheson \& McMclosky, 2008).

\section{Study area and methodology}

\subsection{Study area}

In this study, a national scale approach has been adopted to determine the variables that are more important in causing forest loss in Cameroon. In Cameroon, forest is essentially dominant in the south. As we move northwards, we have the Adamawa region and the North region which are dominated by essentially tropical grassland called Sudan savanna. The region that is south of the Adamawa is covered by tropical grasslands of the Guinea savanna type. The extreme north region is covered by Sahel savanna (Mertens \& Lambin, 2000) (Figure 1). However, we can also find tropical moist deciduous forest in the Adamawa, tropical dry forest in the North and tropical shrub land in the Sahel (FAOSTAT, 2010). Therefore, though most of Cameroon's forest is in the south of the country we also have some in the North which is also of great importance considering the fragile 
nature of the ecosystem. The forests of Cameroon are generally vital because they are part of the Congo basin forest of Africa which remains the second largest stock of tropical rainforest in the world (FAOSTAT, 2010).

\subsection{Data collection}

In an attempt at exploring the relative importance of the different factors responsible for deforestation in Cameroon, several data bases were consulted and used to generate the data. The data on forest area, cattle stock, arable production and permanent crop land, trade in forest products and arable and permanent crop land were obtained from FAOSTAT (www.faostat.org) and the data bases of the World Resource Institute (earthtrends.wri.org). It is worthy of note that most of the data from the FAO is based on country reports which have been criticized as coarse and highly approximative. With this in mind, all FAO data for Cameroon has been verified with those of World Resource Institute for coherence. To further improve the reliability of the data, on the ground observations were carried out and satellite images have been reviewed and in general the results show close correlations with FAO and WRI estimates. The rainfall data was obtained from the climate data base of the school of Geography and the environment of the University of Oxford, collaboration between the latter and the United Nations Development Program (www.country-profiles.geog.ox.ac.uk). Finally, the population data for Cameroon was obtained from the World Bank, World Development Indicators data base (www.google.com/publicdata). All the data used in this study were time series data for each variable covering the period 1961-2000.

\subsection{Data analysis}

To verify the strength of the factors affecting forest area, a multiple linear regression analysis approach was used to determine the effects of the independent factors on the dependent factor. The free $\mathrm{R}$ programming statistical software version 2.12.0 was used to analyze the data. The dependent variable was: Total forest area in hectares. The independent variables were: cattle stock in heads, arable production per capita index in international dollars, fuel wood in cubic metres, arable and permanent crop land in hectares, rainfall in millimeters, population in number of people and trade in forest products/exports in international dollars. The model, variables and regression equation used in the $\mathrm{R}$ programming interface for statistical analysis are:

fit $=\operatorname{lm}($ ForestArea $\sim$ CattleStock + ArableProd + FuelWood + ArablePCL + Rainfall + POPS + Tradeforest $)$

Alternatively, this can be stated as:

$$
\mathrm{FA}=\mathrm{F}(\mathrm{CS}+\mathrm{AP}+\mathrm{FW}+\mathrm{APCL}+\mathrm{RF}+\mathrm{POPS}+\mathrm{TF})
$$

Where:

- $\quad \operatorname{lm}$ is the linear regression model used in the $\mathrm{R}$ interface

- ForestArea (FA) is the Total forest area in thousand hectares (Dependent variable)

- $\quad$ CattleStock (CS) is Cattle stock in thousand heads ( Independent variable)

- ArableProd (AP) is Arable production per capita index in international \$ (Independent variable)

- FuelWood (FW) is fuel wood in thousand cubic metres ( Independent variable)

- ArablePCL (APCL) is arable production and permanent crop land in thousand hectares (Independent variable)

- Rainfall (RF) is rainfall in $\mathrm{mm}$ ( Independent variable)

- $\quad$ POPS (POPS) is the population in number of people (Independent variable)

- Tradeforest (TF) is trade in forest products/exports in international \$ (Independent variable)

The model was run in $\mathrm{R}$ as stated above and this was followed by a sequential removal of variables that showed a lot of collinearity to optimize the model. These variables are removed not because they are unrelated to the dependent variable but because they don't bring in any additional information into the model. This optimization was done by removing variables that had the highest P-value until only those with p-values less than 0.05 remained. The regression models equations used for removal and rerun after removal of variables were as follows:

\#\# Remove Cattle Stock

fit $=\operatorname{lm}($ ForestArea $\sim$ ArableProd + FuelWood + ArablePCL + Rainfall + POPS + Tradeforest $)$ or

$\mathrm{FA}=\mathrm{F}(\mathrm{AP}+\mathrm{FW}+\mathrm{APCL}+\mathrm{RF}+\mathrm{POPS}+\mathrm{TF})$

\#\# Remove Fuel Wood

fit $=\operatorname{lm}($ ForestArea $\sim$ ArableProd + ArablePCL + Rainfall + POPS + Tradeforest $)$ or

$\mathrm{FA}=\mathrm{F}(\mathrm{AP}+\mathrm{APCL}+\mathrm{RF}+\mathrm{POPS}+\mathrm{TF})$ 
\#\# Remove Trade Forest

fit $=\operatorname{lm}($ ForestArea $\sim$ ArableProd + ArablePCL + Rainfall + POPS $)$ or

$\mathrm{FA}=\mathrm{F}(\mathrm{AP}+\mathrm{APCL}+\mathrm{RF}+\mathrm{POPS})$

\#\# Remove Rainfall

fit $=\operatorname{lm}($ ForestArea $\sim$ ArableProd + ArablePCL + POPS $)$ or

$\mathrm{FA}=\mathrm{F}(\mathrm{AP}+\mathrm{APCL}+\mathrm{POPS})$

As seen above, the final model included Population, arable and permanent crop land and arable production per capita index. The variables removed included cattle stock, fuel wood, trade in forest products/exports and rainfall. A correlation matrix was created on the data; this was done to see the degree of correlation that exists between all the variables included in the study. The equation used to create this was as follows:

\#\# Create a correlation matrix for the data

cor (raw_dat)

Where: cor stands for correlation in the $\mathrm{R}$ interface and raw_dat represents the raw data used in the calculations.

Finally, to determine the strength of the model in predicting the variables and their effects on forest area, power analysis was employed. Normally with an $\mathrm{R}^{2}$ that is close to 1 , it can be said that the model is exceptionally powerful. However, to verify this, the power analysis approach was used and run in R. The formula (Cohen, 1988) and procedure for such calculations is as follows:

$>$ \#\# Power Analysis of Final model

$>$ fit $=\operatorname{lm}($ ForestArea $\sim$ ArableProd + ArablePCL + POPS $)$

$>$ effect=Rsqr/ (1-Rsqr)

Where: $\mathrm{Rsqr}=\mathrm{R}^{2}$ (Coefficient of determination)

$\mathrm{u}=$ Degree of freedom of numerator or sample (computed into $\mathrm{R})=3$

$\mathrm{v}=$ Degree of freedom of the denominator (computed into $\mathrm{R})=36$

Level of significance (computed into $\mathrm{R})=0.05$

\section{Results}

\subsection{Time series plots of independent and dependent variables}

The variables included in the multiple linear regression equation were plotted over time to illustrate their trends. Eight time series plots were obtained. It is observed that the dependent variable which is the forest area is perfectly linear. This is explained by the fact that this model assumed a yearly loss in forest area of 220000 hectares inspired from (FAO, 1990; FAO, 2010). For the first four (Figure 2a) variables the following observations were made. Cattle stock on its part is generally increasing, though there is a significant variation in the rate of increase from year to year. This is explained by the fact that keeping cattle is an economically enriching activity and as a result years of profit made encourage more production. Arable production per capita index is highly variable, it was rising in the beginning right up to around 1974 and thereafter it begins to decline. This trend is explained by the reduced productivity of soils and lack of fertilizers and other farm inputs, farmers are forced to rely on natural soil fertility and ash from slash and burn cultivation. Fuel wood on its part was constant in the beginning and then experienced a rise explained by the fact that fuel wood is a very important source of energy to most households in Cameroon.

For the last four variables (Figure 2b) it is observed that arable and permanent crop land rose steadily during the first half and leveled. The leveling could be explained by the implementation of policies to halt continual expansion of farm land in an attempt to reduce forest lost; this coincided with the production of the national environmental management plan which stated strict measures to stop deforestation. Rainfall on its part is generally within 120-150 mm throughout the period. The generalized tend is one of a "white noise" which depicts a very variable random variable as it hardly correlates with any of the variables significantly. The population trend on the other hand depicts an increasing population over the entire period. In 1961 the population was about 5 million people but by 1984 it had doubled itself and stood at about 10 million while by 2000 it was about 15 million people. Trade in forest products was greatly increasing but also in a highly variable manner. The variations are explained by periods of low profitability in wood exports. 


\subsection{Scatter plot matrices between various independent factors and forest area}

A simple scatter plot matrix (Figure 3) was created to look for relationships among all of the variables. From the observed correlations, we notice that almost all the variables are interrelated. The only plots that appear to have weak trends are the plots of all other variables against rainfall. The rest of the variables seem to cause a decline in forest area. Both population and cattle stock appear to be highly collinear with forest area. This is indicative of the fact that both population and cattle stock are closely correlated. When population rises, cattle stock rises and this also causes a declining linear forest area to be observed. We have already said that this is due to the fact that the model assumes that forest area is declining by 220000 hectares.

The following observations are made for the interactions between population and forest area on the one hand and cattle stock and forest area on the other (Figure 4). The fact that the cattle stock component spirals around the best fit line suggest a cyclical component which in this case could be explained by years of increase cattle stock followed by years of low cattle stock and years of low cattle stock followed by years of increase cattle stock. There is therefore a possibility for high dependence between cattle stock and population as both variables seems to be highly correlated. This will however be confirmed when a correlation matrix will be built.

Similarly, arable and permanent crop land and fuel wood also seems to be increasing over time generally. However, when fuel wood was constant, arable and permanent crop land was rising while when fuel wood was rising, arable and permanent crop land was constant (Figure 5).

\subsection{Correlation matrix of independent and dependent variables}

From the correlation matrix (Table 1), cattle stock has a correlation of $(\mathrm{r}=-0.98)$ with forest area, fuel wood has a correlation of $(r=-0.81)$ with forest area, population has a correlation of $(r=-0.98)$ with forest area and trade in forest products/exports has a correlation of $(\mathrm{r}=-0.86)$ with forest area. The implication of these results is that all these variables are strongly negatively correlated with forest area and as such when they increase, forest area decreases.

Generally, many of the independent variables are highly correlated with each other. This suggests that multi-collinearity is a significant problem in building a multiple regression model. In the same way, Pearson correlation coefficients as low as 0.8 will be problematic if placed in the model. Removal of variables will be considered during the stepwise process utilized to build the regression model.

\subsection{Multiple linear regression models of forest area and the independent variables}

The first run of the multiple linear regression models considered all the seven independent variables listed on Table 2a relative to the dependent variable and the results obtained from the runs are as follows. There is a p-value of essentially zero on an F-statistic of 3486 which shows that the model is significant. This is further supported by a coefficient of determination or Multiple R-square of 0.9887 . The P-value of cattle stock is listed as 0.945 . This number should not be interpreted as meaning cattle stock is not significantly related to forest area, rather, what is happening is that cattle stock is so highly correlated to population such that as stated earlier collinearity arises. This high P-value means that with population in the model, cattle stock does not bring in enough new information to justify its inclusion. However, the three most significant variables that influence forest area as per this model are arable production per capita index, arable and permanent crop land and population. With the stepwise exclusion of some variables, these results may be different; they warrant a rerun because of collinearity and interdependence of among some independent variables. Table $2 \mathrm{a}$ shows these results.

The variables that were removed to optimize the model are, cattle stock, fuel wood, trade in forest products/ exports and rainfall. The final model therefore included population, arable and permanent crop land, and arable production per capita index, essentially the variables that were dominant in the first run. From the rerun, we observe that there is an R-Squared of 0.9885 . This implies that the model containing only these three variables significantly explains the variations in forest area. From the individual t-values, we observe that population stands out as the most influential independent variable affecting forest area; this is followed by arable and permanent crop land and finally by arable production per capita index (Table $2 b$ ).

To determine the strength of the model, a power test was run. However, it is intuitive that, with an $\mathrm{R}^{2}$ value of nearly 1 , the power of this model is exceptionally high. However, it is still necessary to verify this. To do so, the $\mathrm{R}$ statistic power package was utilized. This method calculates power using the methods outlined by Cohen, (1988). The output is shown below. The result of the power test is estimated as 1, showing that the model is still highly significant in predicting deforestation. Whatever the case, this model suffers from multi-collinearity and interdependence among some of the independent variables as well as the fact that the trends in the annual change of forest area are set at a constant rate of 220000 hectares per year. To overcome these difficulties, some of these variables have been dropped in the later model. 


\section{Discussions}

In summary, the linear regression model shows that population is the most significant cause of deforestation in Cameroon. This is because as population grows, the need for more land for settlement, agriculture inter alia increases. According to index mundis, a free online data base available on (www.indexmundi.com) Cameroon had a population growth rate of $2.12 \%$ in 2011 and $2.47 \%$ in 2000 . Other studies have reported similar results that support this view point. Allen \& Barnes (1985) used a multiple regression approach to confirm that increase in population was more associated to loss in forest area in Africa and Asia while arable expansion was also considered as the second variable. Acheson \& McClosky, (2008) also conclude in their study on the causes of deforestation in Maine that population growth is a major trigger. In Bangladesh, it is reported that population growth poses a big problem of over exploitation of forest resources as extreme population growth has been eating up forest resources at a rate faster than they can be regenerated. Increase arable land is also considered as a factor of importance, it is argued that the quest is driven by the rapidly growing population (Salam \& Noguchi, 1998). Furthermore, population dynamics have been widely considered as elements in land cover change dynamics. In fact, population has been described in the literature as one of the significant drivers of global deforestation (Carr et al., 2005; Vanclay, 1993; Houghton, 1991; Zhao et al., 2006). Other studies argue that population growth explains more than half of the loss in forest area worldwide (Mather et al., 1998; Myers, 1991). However, Angelsen \& Kaimowitz (1999) argue that in addition to population it would be good to consider other factors such as cropland expansion and cattle ranching.

Other factors that are considered important are arable and permanent crop land as well as arable production per capita index which are second and third most valuable factors that explain deforestation in Cameroon. This result is highly consistent with other studies. A study carried out in Central Argentina reports that the agricultural expansion for the purpose of cultivating Soya beans in particular is the main proximate cause of forest loss (Zak et al., 2008); a view supported by Geist \& Lambin (2002), when they report that about $96 \%$ of deforestation in Africa, Asia and Latin America is caused by agricultural expansion. As such, agricultural expansion remains a vital cause of deforestation and it at times comes up due to population pressure. In supporting the latter notion it has been stated that one of the principal causes of deforestation in Panama has been the expansion of agricultural frontiers through extensive shifting cultivation systems. The study adds that the land use systems are becoming increasingly problematic because as population rises, the amount of agricultural land available for use declines and this triggers deforestation in search for more land and fuel wood (Fischer \& Vasseur, 2000). The role of fuel wood in Sub-Saharan African has been explored in the literature. About 90 percent of the population in sub-Saharan Africa use fuel wood which contributes about 52\% of the entire African energy budget (Agvei, 1997).

\section{Conclusions}

This study shows that the most significant causes of loss in forest area in Cameroon are population growth, arable and permanent crop land and arable production per capita index. The statistical models have proven this result. Currently, forest degradation in Cameroon is persistent and lack of knowledge of the actual causes has made attempts at reducing deforestation generalized, simplistic and the repercussions of food and water scarcity persist.

With these results, it therefore becomes possible for the government of Cameroon to target policies towards ones that will meet the needs of the populations by taking them off forest lands in attempts to create more space for agricultural expansion. If the government ignores this, the ecological consequences of deforestation will persist and further forest area loss will be the result. Therefore, policies that will reduce the rate at which the growing population encroaches on forested land should be enacted. These should however be in a context where the population is given more access to farm inputs such as fertilizers and machinery to enhance output on the same land.

Other possible independent variables not considered by these models are soil erosion, wild fires, acid rains and loss in soil fertility. These variables may affect forest loss, arable production and arable and permanent crop land. However, due to the difficulties associated with calculating these variables, inclusion in the model and multi-collinearity, these variables have been left out of this current study.

\section{Acknowledgements}

This research is financed by the Resources and Environmental management trust merit based scholarship program of Cameroon, the NSERC Canada discovery grant, the ECO-MCS Laboratory of the University of Quebec in Montreal and the FARE scholarship board of the University of Quebec in Montreal. 
Special thanks go to the following organizations that have financed this study, the resource and environmental management trust merit based scholarship program of Cameroon, the NSERC Canada discovery grant, the ECO-MCS Laboratory of the University of Quebec in Montreal and the FARE scholarship board of the University of Quebec in Montreal. I also want to thank Dr. Zhiha Ma and Mrs. Lynetta Campbell for their insightful proposals on statistical methods.Thanks also go to Marline Mbinze Epule and Mirielle Epule for all their support in improving the manuscript.

\section{References}

Acheson, J. M., \& McClosky, J. (2008). Causes of Deforestation: The Maine case. Human Ecology, 36, 909-922. doi:10.1007/s10745-008-9204-3, http://dx.doi.org/10.1007/s10745-008-9204-3

Agarwal, D. Y., et al. (2005). Tropical deforestation in Madagascar: analysis using hierarchical, spatially explicit, Bayesian regression models. Ecological modeling, 185, 105-131.

Agvei, Y. (1997). Deforestation in Sub-Saharan Africa. African technology forum. The information source for the Science and Technology in Africa, Vol 8, No 1 of AFT. [Online] Available: http://web.mit.edu/africantech/www/articles/Deforestation.htm (June 12, 2011)

Allen, J. C., Barnes, D. F. (1985). The causes of Deforestation in developing countries. Annals of the Association of American Geographers, 75, 163-184. doi:10.1111/j.1467-8306.1985.tb00079.x, http://dx.doi.org/10.1111/j.1467-8306.1985.tb00079.x

Angelsen, A., Kaimowitz, D. (1999). Rethinking the causes of Deforestation: Lessons from economic models. The World Bank Observer, 14, 73-98.

Armenteras, D., Rodriguez, N., Retana, J., \& Morales, M., (2010). Understanding deforestation in montane and lowland forest of the Colombian Andes. Reg Environ Change, doi: 10.1007/s10113-010-0200-y, http://dx.doi.org/10.1007/s10113-010-0200-y

Carr, D., Suter, L., \& Barbieri, A. (2006). Population Dynamics and Tropical Deforestation: State of the Debate and Conceptual Challenges. Population and Environment, 27, 90-113.

Clement, F., \& Amezaga, J. M. (2008). Linking reforestation policies with land use change in northern Vietnam: Why local factors matter. Geoforum, 39, 265-277. doi:10.1016/j.geoforum.2007.05.008, http://dx.doi.org/10.1016/j.geoforum.2007.05.008

Cohen, J. (1988). Statistical power analysis for the behavioral sciences. (3r ed.). Hillsdale, NJ: Lawrence Erlbaum Associates. (Chapter 1, 2, 3)

Fischer, A. \& Vasseur, L. (2000). The crisis in shifting cultivation practices and the promise of agroforestry: a review of the Panamanian experience. Biodiversity and Conservation, 9, 739-756. doi:10.1023/A:1008939425511, http://dx.doi.org/10.1023/A:1008939425511

Food and Agricultural Organisation of the United Nations. (1990). Forest Resource Assessment. FAO Forestry papers no 112, FAO, Rome. [Online] Available http://www.fao.org (May 10, 2011)

Food and Agricultural Organisation of the United Nations. (2010). FAOSTAT. [Online] Available http://faostat.org (March 16, 2011)

Food and Agricultural Organisation of the United Nations. (2010). Forest Resource Assessment. FAO Forestry paper no 163, FAO, Rome. [Online] Available http://www.fao.org (May 12, 2011)

Geist, H. J., \& Lambin, E. F. (2002). Proximate causes and underlying driving forces of tropical deforestation. Bio Science, 52, 143-150. doi:10.1641/0006-3568(2002)052[0143:PCAUDF]2.0.CO;2, http://dx.doi.org/10.1641/0006-3568(2002)052[0143:PCAUDF]2.0.CO;2

Houghton, R. A. (1991). Tropical deforestation and atmospheric carbon dioxide. Climate Change, 19, 99-118. doi:10.1007/BF00142217, http://dx.doi.org/10.1007/BF00142217

Lambin, E., \& Ehrlich, D. (1997). The identification of tropical deforestation fronts at broad spatial scales. International Journal of remote sensing, 18(17), 3551-3568. doi:10.1080/014311697216793, http://dx.doi.org/10.1080/014311697216793

Mather, A. S., Needle, C. L., \& Fairbairn, J. (1998). The human drivers of global land cover change: the case of forests. Hydrological processes, $\quad 12,14$. doi:10.1002/(SICI)1099-1085(19981030)12:13/14<1983::AID-HYP713>3.0.CO;2-M, http://dx.doi.org/10.1002/(SICI)1099-1085(19981030)12:13/14<1983::AID-HYP713>3.0.CO;2-M 
Mertens, B., \& Lambin, E. (1997). Land-Cover Trajectories in Southern Cameroon. Annals of the Association of American Geographers, 90(3), 467-494. doi:10.1111/0004-5608.00205, http://dx.doi.org/10.1111/0004-5608.00205

Mertens, B., \& Lambin, E. (1997). Spatial modeling of deforestation in southern Cameroon: Spatial disaggregation of diverse deforestation processes. Applied Geography, 17(2), 143-162. doi:10.1016/S0143-6228(97)00032-5, http://dx.doi.org/10.1016/S0143-6228(97)00032-5

Mundex Dataset. (2011). Growth rate of the Population of Cameroon. [Online] Available: www.indexmundi.com (April 20, 2011)

Myers, N. (1991). Tropical forests: Present status and future outlook. Climate Change, 19(1-2), 3-32. doi:10.1007/BF00142209, http://dx.doi.org/10.1007/BF00142209

Oyono, R. P. (2005). Profiling Local-Level Outcomes of Environmental Decentralizations: The Case of Cameroon's Forests in the Congo Basin. The Journal of Environment Development, 14, 317-337.

Salam, A., \& Noguchi, T. (1998). Factors Influencing the Loss of forest Cover in Bangladesh: An Analysis from Socioeconomic and Demographic Perspective. Journal of Forest Research, 3, 145-150. doi:10.1007/BF02762135, http://dx.doi.org/10.1007/BF02762135

United Nations Development program. (2011).Rainfall data country profiles. Department of Geography, Oxford University. [Online] Available: www.country-profiles.geog.ox.ac.uk (March 20, 2011)

Vanclay, J. (1993). Saving the tropical forest: Needs and Prognosis. Ambio, 22(4), 225-231.

World Bank. (2011).World Development Indicators. World Bank, [Online] Available: www.google.com/publicdata (March 20, 2011)

Zak, R. M., Cabido, D. C., \& Diaz, S. (2008). What Drives Accelerated Land Cover Change in Central Argentina? Synergistic Consequences of Climatic, Socioeconomic, and Technological Factors. Environmental Management, 42, 181-189. doi:10.1007/s00267-008-9101-y, http://dx.doi.org/10.1007/s00267-008-9101-y

Zhao, S., Peng, C., Jiang, D.T., Lei, X., \& Zhou, X. (2006). Land use change in Asia and ecological consequences.Eco Res, doi:10.1007/s11284-006-0048-2, http://dx.doi.org/10.1007/s11284-006-0048-2

Table 1. Correlation Matrix for All Variables under study

\begin{tabular}{|c|c|c|c|c|c|c|c|c|}
\hline & $\begin{array}{c}\text { Forest } \\
\text { Area }\end{array}$ & $\begin{array}{c}\text { Cattle } \\
\text { Stock }\end{array}$ & $\begin{array}{c}\text { Arable } \\
\text { Prod }\end{array}$ & $\begin{array}{c}\text { Fuel } \\
\text { Wood }\end{array}$ & ArablePCL & Rainfall & POPS & Tradeforest \\
\hline $\begin{array}{c}\text { Forest } \\
\text { Area }\end{array}$ & 1.000000 & -0.980146 & 0.599922 & -0.811511 & -0.932501 & 0.390394 & -0.988402 & -0.86029 \\
\hline $\begin{array}{c}\text { Cattle } \\
\text { Stock }\end{array}$ & -0.9801468 & 1.0000000 & -0.660475 & 0.7764691 & 0.9282093 & -0.400914 & 0.9717055 & 0.827427 \\
\hline $\begin{array}{c}\text { Arable } \\
\text { Prod }\end{array}$ & 0.5999224 & -0.660475 & 1.0000000 & -0.584086 & -0.563462 & 0.2494452 & -0.644580 & -0.54322 \\
\hline $\begin{array}{c}\text { Fuel Wood } \\
\text { ArablePCL }\end{array}$ & -0.8115119 & 0.7764691 & -0.584086 & 1.000000 & 0.5573615 & 0.0727502 & 0.8841214 & 0.924979 \\
\hline Rainfall & 0.3903945 & -0.400914 & 0.2494452 & -0.072750 & -0.516061 & 1.0000000 & -0.341375 & -0.08734 \\
\hline POPS & -0.9884027 & 0.9717055 & -0.644580 & 0.884121 & 0.8756269 & -0.341375 & 1.0000000 & 0.901929 \\
\hline Tradeforest & -0.8602946 & 0.8274278 & -0.543221 & 0.924979 & 0.6749045 & -0.087341 & 0.9019299 & 1.000000 \\
\hline
\end{tabular}

Shows Pearson correlation for the eight variables under consideration. The unknowns with abbreviations are Arable Prod which stands for Arable production per capita index and ArablePCL stands for Arable and permanent crop land in hectares, POPS which represents population and Tradeforest which represents trade in forest products in international \$.POP, Cattle stock, fuel wood ArablePCL, Tradeforest are strongly negatively correlated with forest area. 
Table 2a. First run of linear regression model with all independent variable

\begin{tabular}{|l|l|l|l|l|}
\hline Variables & Coefficient & \multicolumn{1}{|c|}{ Standard Error } & t- value & p-value \\
\hline Cattle Stock & $-6.706 \mathrm{e}-03$ & $9.575 \mathrm{e}-02$ & -0.070 & 0.945 \\
\hline Arable Prod & $-1.962 \mathrm{e}+01$ & $2.819 \mathrm{e}+00$ & -6.960 & $6.96 \mathrm{e}-08 * * *$ \\
\hline FuelWood & $-1.833 \mathrm{e}-01$ & $1.995 \mathrm{e}-01$ & -0.919 & 0.365 \\
\hline ArablePCL & $-1.451 \mathrm{e}+00$ & $2.247 \mathrm{e}-01$ & -6.458 & $2.90 \mathrm{e}-07 * * *$ \\
\hline Rainfall & $-3.905 \mathrm{e}+00$ & $2.617 \mathrm{e}+00$ & -1.492 & 0.145 \\
\hline POPS & $-5.633 \mathrm{e}-04$ & $1.008 \mathrm{e}-04$ & -5.588 & $3.58 \mathrm{e}-06 * * *$ \\
\hline Tradeforest & $4.846 \mathrm{e}-04$ & $3.923 \mathrm{e}-04$ & 1.235 & 0.226 \\
\hline
\end{tabular}

Total number of independent variables $=7$, Residual standard error $=102.5$,

Degree of freedom $=32$, Multiple R-Squared $=0.9887$, Adjusted R-Squared $=0.9984$,

F Statistic $=3486$, on 7, P-value $=<2.2 \mathrm{e}-16$, Significant codes $=*$

Residuals:

$$
\begin{array}{lllll}
\text { Min } & \text { 1Q } & \text { Median } & \text { 3Q } & \text { Max } \\
-157.541 & -68.390 & -9.338 & 72.475 & 248.269
\end{array}
$$

Table $2 b$. Final run of linear regression model with the three most significant independent variables

\begin{tabular}{|l|l|l|l|l|l|}
\hline Variables & Coefficient & Standard Error & $\mathrm{t}$-value & $\mathrm{p}$-value & Rank of t-value \\
\hline Arable Prod & $-1.882 \mathrm{e}+01$ & $2.490 \mathrm{e}+00$ & -7.557 & $6.19 \mathrm{e}-09 * * *$ & 3 \\
\hline ArablePCL & $-1.215 \mathrm{e}+00$ & $5.596 \mathrm{e}-02$ & -21.704 & $<2 \mathrm{e}-16 * * *$ & 2 \\
\hline POPS & $-6.255 \mathrm{e}-04$ & $1.150 \mathrm{e}-05$ & -54.414 & $<2 \mathrm{e}-16 * * *$ & 1 \\
\hline
\end{tabular}

Total number of independent variables $=3$, Residual standard error $=102.4$,

Degree of freedom $=36$, Multiple R-Squared $=0.9885$, Adjusted R-Squared $=0.9984$,

F Statistic $=8156$, on 3, P-value $=<2.2 \mathrm{e}-16$, significant codes $=*$

Residuals:

$$
\begin{array}{lllll}
\text { Min } & \text { 1Q } & \text { Median } & \text { 3Q } & \text { Max } \\
-138.338 & -92.888 & -6.522 & 72.171 & 259.645
\end{array}
$$

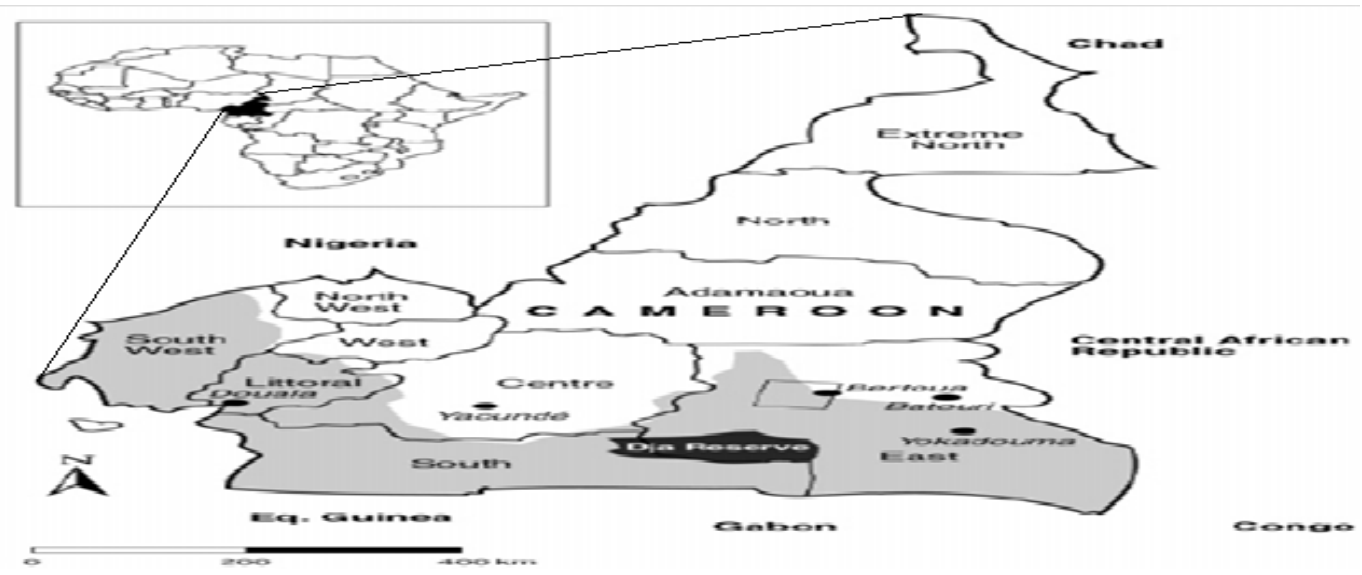

Figure 1. Map of Cameroon showing approximate spatial extent of the forest area shaded in light grey. The regions to the north are dominated by essentially tropical grassland ranging from Sudan savanna in the Adamawa and North regions, Sahel savanna in the Extreme North and Guinea savanna in the transition zone between the south of the country and the north of the country Source: Modified from Mertens \& Lambin, (2000) 
Time Series Data for Forest Area

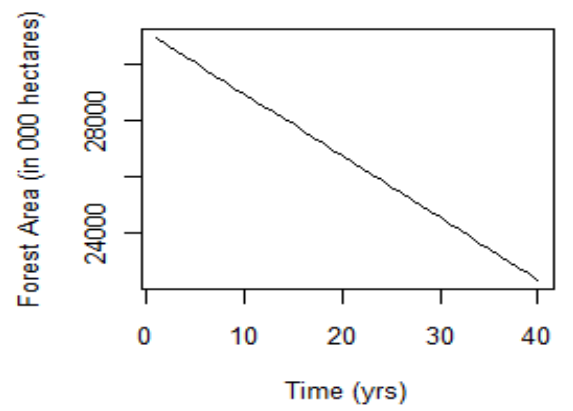

Time Series Data for Arable Prod

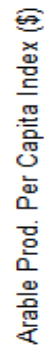

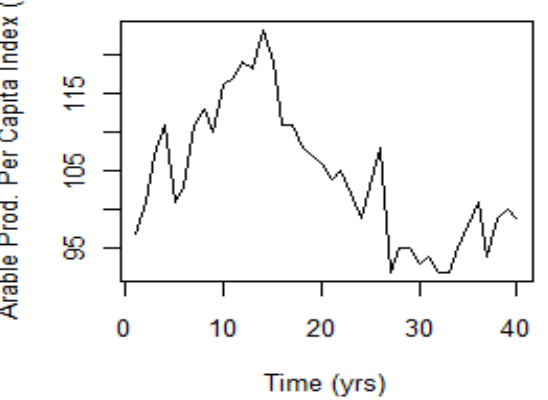

Time Series Data for Cattle Stock

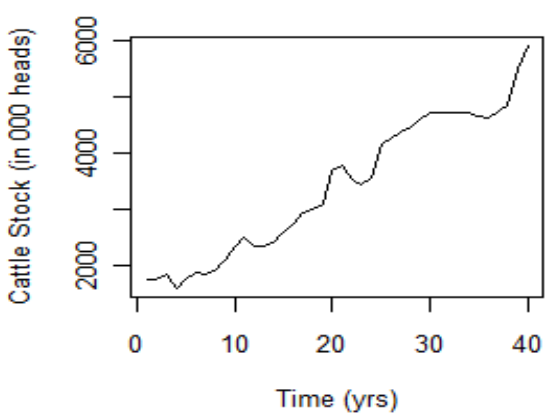

Time Series Data for Fuel Wood

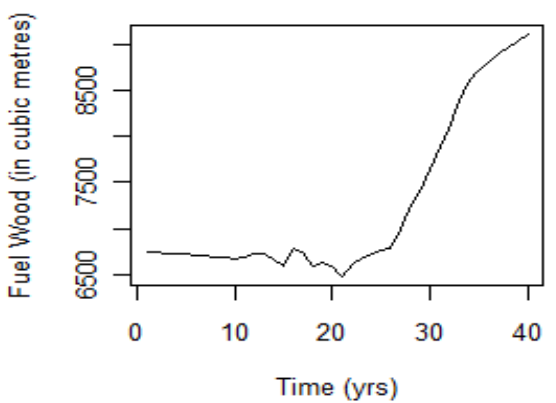

Figure 2a. Time series plots of forest area, cattle stock, arable production and fuel wood. The years range from 1961-2000. Note that 0 years on years axis represents 1960, 10 years represents 1970, 20 years represents 1980, 30 years represents 1990 and 40 years represents 2000

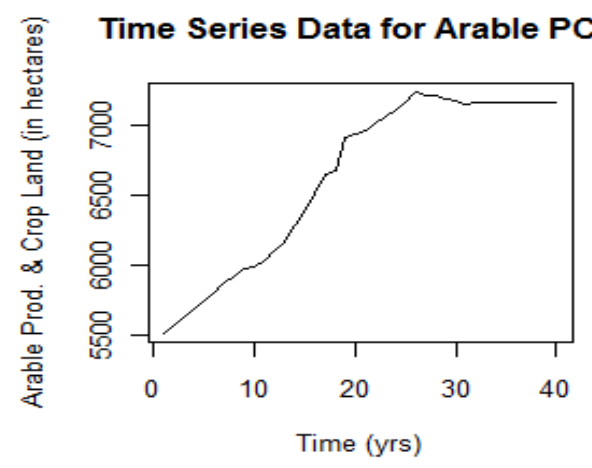

Time Series Data for Rainfall

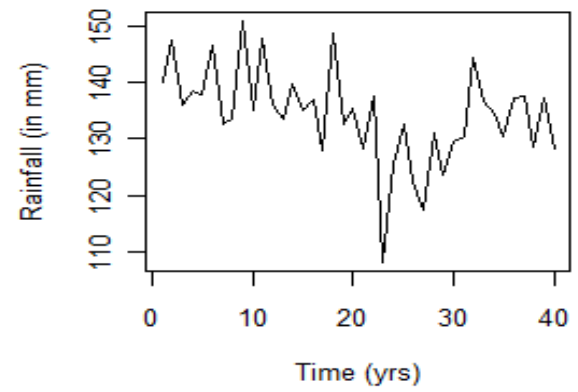

Time Series Data for POPS
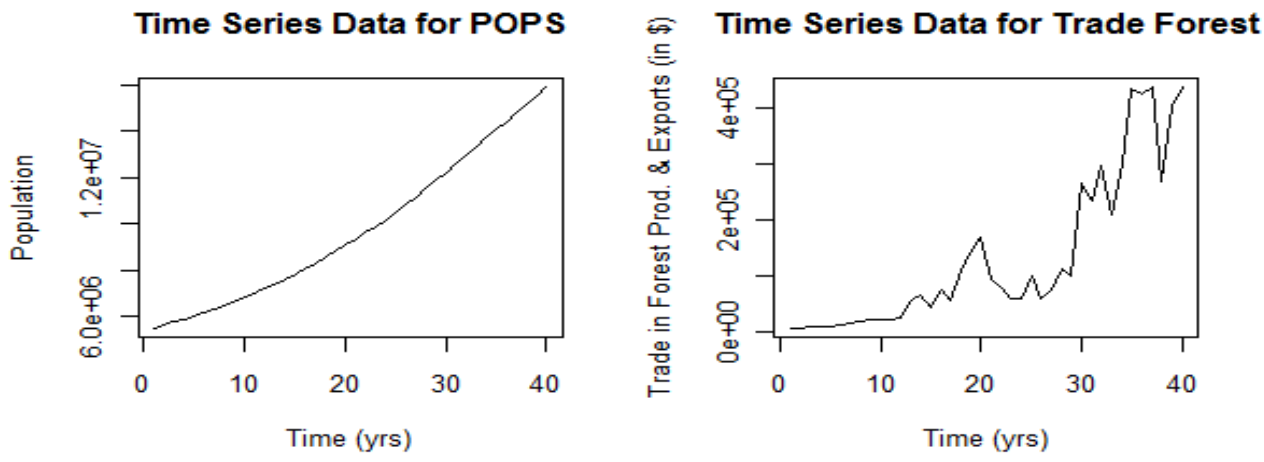

Figure $2 b$. Time series plots of Arable and permanent crop land, rainfall, population and trade in forest products. The years range from 1961-2000. Note that 0 years on the years axis represents 1960, 10 years represents 1970, 20 years represents 1980, 30 years represents 1990 and 40 years represents 2000 


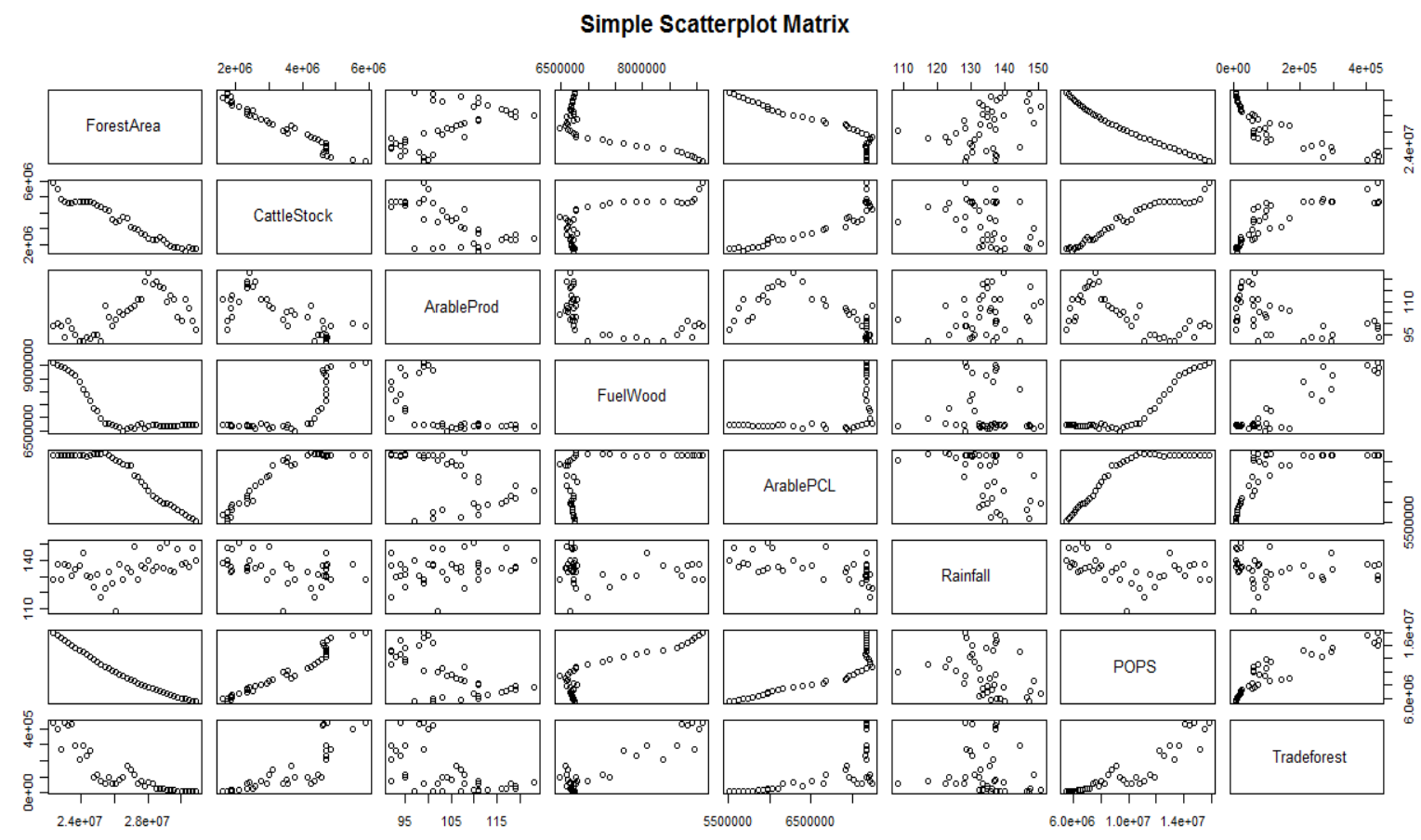

Figure 3. Scatter plot matrix illustrating relationships between all pairs of variables. We observe that all variables have a negative correlation with forest area except rainfall
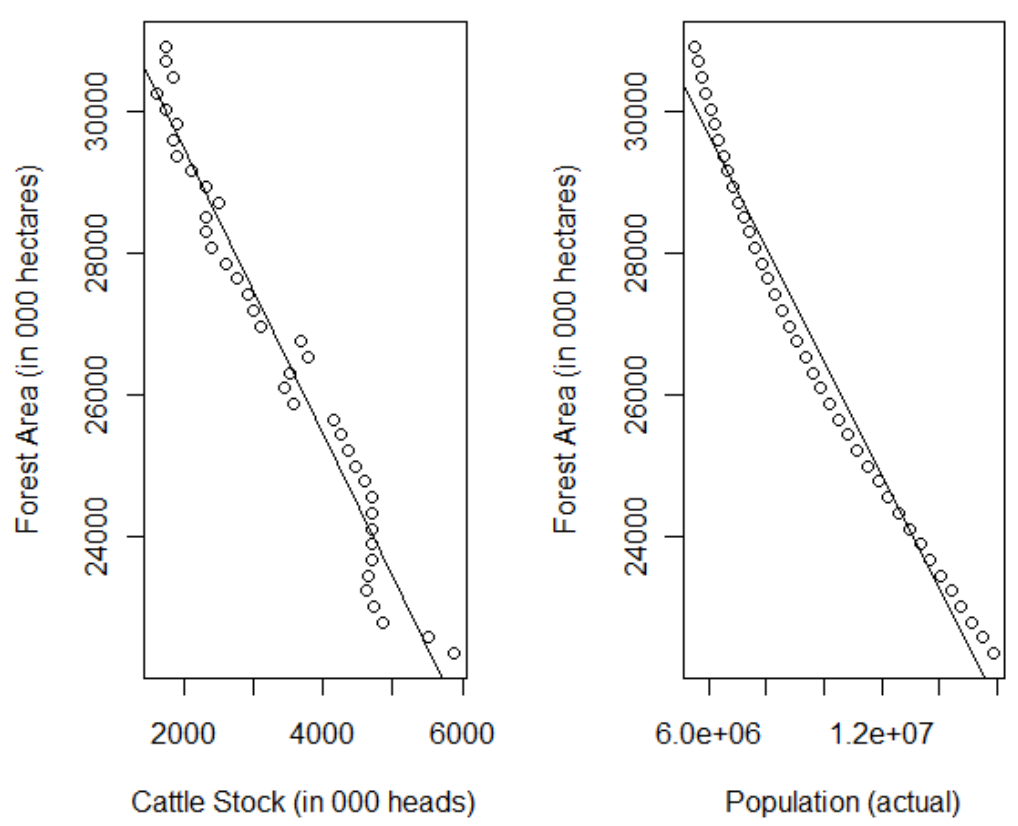

Figure 4. Scatter plots of Cattle Stock and population against Forest Area. Scatter plots with best fit lines showing a generalized trend of decline in forest area with increase cattle stock and population 


\section{Scatter Plots with Lowess Curves}
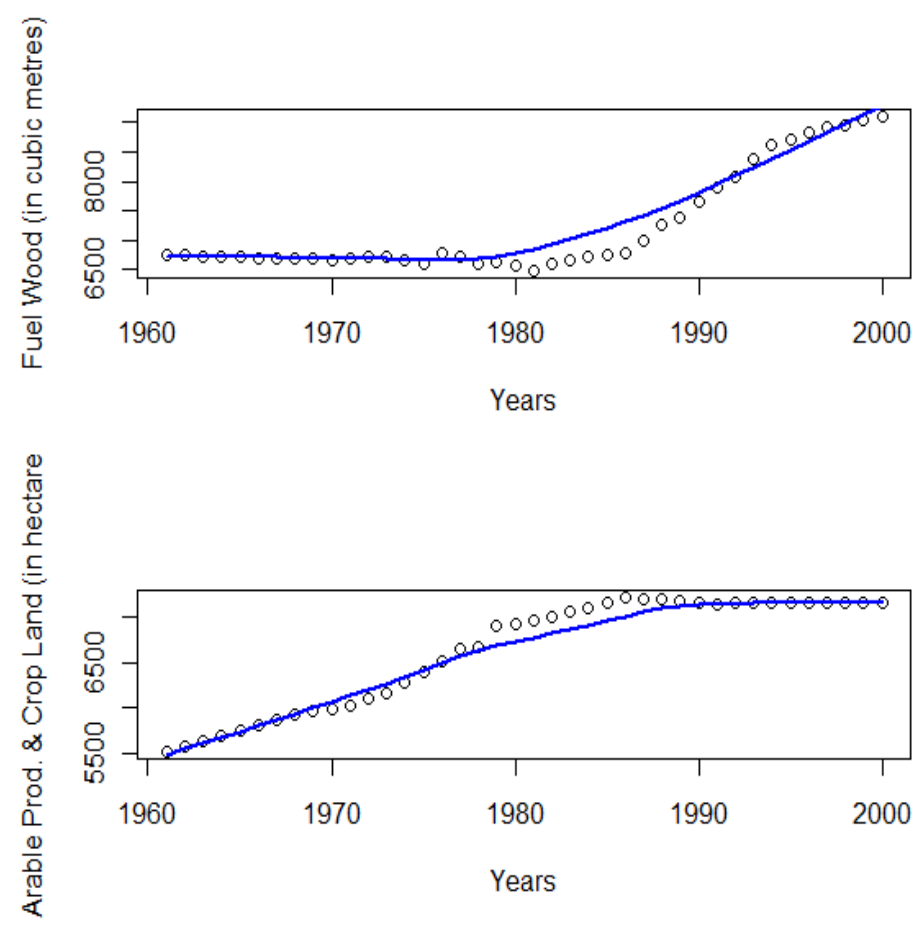

Figure 5. Time plots for Fuel Wood and Arable PCL. Scatter plots with Lowess curves. We observe that when fuel wood is constant arable production and permanent crop land is rising and when fuel wood is rising arable production and permanent crop land is constant 